\title{
DINÂMICAS INTERACIONAIS DO BULLYING ENTRE MENINAS: EXPLORANDO AS TRAMAS DO APRENDIZADO DE GÊNERO
}

\section{Resumo}

Neste estudo, analisa-se como meninas entre 11 e 15 anos manejam o bullying como mecanismo socializador, que classifica os pares em um jogo de diferenças e oposições. Trata-se de uma pesquisa etnográfica realizada em duas escolas públicas das capitais dos Estados de São Paulo e Salvador, Brasil. Práticas de bullying configuram uma forma de interação que as ordena socialmente, por meio da regulação da sexualidade. Nesse contexto, as disputas por poder estruturam a prescrição de modos de ser menina e definem posições na hierarquia social. A micropolítica instaurada nessa disputa evidencia como controle e punição sociais conduzem ao aprendizado de representações convencionais de feminilidade.

Palavras-chave: Bullying, gênero, sexualidade, socialização, adolescência.

\section{Abstract \\ Interactive Dynamics of Bullying Among Girls: Exploiting the Plots of Learning Gender}

This study analyzes how girls between 11 and 15 years old manage bullying as a socializing mechanism, which classifies the peers into a game of differences and oppositions. It is an ethnographic research carried out in two public schools of the states of São Paulo and Salvador, Brazil. Bullying practices constitute a form of interaction that orders them socially, through the regulation of sexuality. In this context, disputes over power structure the prescription of ways of being girl and define positions in the social hierarchy. The micropolitics established in this dispute shows how social control and punishment lead to the learning of conventional representations of femininity.

Keywords: Bullying, gender, sexuality, socialization, adolescence.

\section{Resumen}

Dinámicas Interactivas del Acoso Escolar entre Chicas: Explorando las Tramas del Aprendizaje de Género

Este estudio analiza cómo las chicas entre 11 y 15 años operan el acoso escolar como mecanismo socializador, que clasifica a los pares en un juego de diferencias y oposiciones. La pesquisa etnográfica fue realizada en dos escuelas públicas de las capitales estaduales brasileñas São Paulo y Salvador. Las prácticas de acoso configuran una forma de interacción que las ordena socialmente, por medio de la regulación de la sexualidad. En

\footnotetext{
Departamento de Saúde, Ciclos de Vida e Sociedade, Faculdade de Saúde Pública (FSP-USP), Universidade de São Paulo, Brasil.

Endereço postal: Departamento de Saúde, Ciclos de Vida e Sociedade, Avenida Doutor Arnaldo, 715, 2. ${ }^{\circ}$ andar, sala 203, São Paulo - SP - CEP: 01246-904, Brasil.

Endereço eletrónico: mile.guimaraes@gmail.com
} 
ese contexto, las disputas por poder estructuran la prescripción de modos de ser chica y definen posiciones en la jerarquía social. La micropolítica instaurada en esa disputa evidencia como el control y castigo social conducen la introyección de representaciones convencionales de feminidad.

Palabras clave: Acoso escolar, género, sexualidad, socialización, adolescencia.

\section{Introdução}

Nas últimas décadas tem havido um interesse crescente em explorar e compreender as maneiras pelas quais as meninas se envolvem em atos violentos (Neves 2008; Simmons 2011). A discussão acerca de uma aparente escalada de agressividade constitui um terreno de representação complexo e contraditório, espaço de um novo pânico moral que gira em torno da demarcação dos limites e possibilidades do que significa ser menina.

A realização adequada da feminilidade envolve qualidades idealizadas de menina como boa, carinhosa, sexualmente inocente ou respeitável (Tolman 2005; Schalet 2009). Esta condição normativa desenvolve uma suposta naturalidade da afabilidade feminina, enquanto demanda para que debelem expressões de frustração, raiva e fúria. Como descrito no estudo de Ringrose (2008), as meninas que recorrem a violência física ou confrontos ostensivos estão sob o risco de serem constituídas como desviantes de seu gênero.

O bullying entre meninas tem sido referido como «agressão relacional», definida como uma manipulação feita com a intenção de prejudicar relacionamentos ou sentimentos de aceitação, amizade ou inclusão no grupo de pares (Simmons

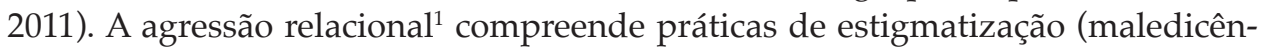
cias, xingamentos) e de exclusão social fundamentadas no dano à reputação de outra pessoa. A reputação é sumamente relevante nas relações entre pares, pois constitui uma forma indireta de obter benefícios sociais tangíveis como status, popularidade e possibilidades românticas (Duncan 2004; Currie et al. 2007).

Como apresentado nos trabalhos de Miller (2016) e Miranda e Maia (2017), várias das agressões que ocorrem entre os estudantes estão associadas às relações de gênero e colocam em prática a forma de os envolvidos desempenharem a sua feminilidade ou masculinidade. Tal dinâmica de interações informa o funcionamento das relações e normas de gênero não apenas entre meninos e meninas, mas sobretudo nos momentos de homossociabilidade. A fase inicial da adolescência é marcada pela intensificação da construção da identidade de gênero e da iniciação da vida sexual, reforçando a atuação do bullying tanto como uma prática quanto um processo de gênero. Enquanto prática cultural juvenil, consti-

Neste estudo, me referirei a essa modalidade apenas como «bullying» ou «bullying relacional» por não considerar produtivo utilizar outro termo para nomear um subtipo desta violência. 
tui uma importante ferramenta de negociação de papéis e status nos grupos de pares (Duncan 2004; Goodwin 2006), ao passo que, como processo, contribui na produção e regulação de significados sobre normas e expectativas de gênero (Ringrose 2008; Santos et al. 2017), informando aos jovens como o gênero deve - e não deve - ser desempenhado.

A sexualidade cumpre um papel significativo em experiências de bullying. Entre os meninos, a intersecção entre bullying, sexualidade e regulação de gênero tem sido amplamente documentada. Diversos estudos têm delineado o bullying homofóbico e misógino como mecanismo para a construção e o controle de masculinidades entre rapazes (Pascoe 2007; Santos et al. 2017). As práticas de intimidação entre meninas também são mediadas por discursos sobre sexualidade, majoritariamente relativos a condutas promíscuas (Armstrong et al. 2014; Miller 2016). Especialmente no contexto ibero-americano, as intersecções entre gênero e sexualidade nas experiências de meninas com bullying permanecem pouco exploradas.

Embora o bullying seja frequentemente interpretado como um "problema» de crianças e adolescentes, seu conteúdo reflete ideologias e códigos culturais hegemônicos. Há de se atentar a como ele reflete, reproduz e prepara os mais jovens para aceitar as desigualdades embutidas em estruturas sociais mais amplas. Afinal, ao negar a alteridade na relação entre pares, o bullying imputa a aproximação do alvo à normalidade. E é a partir desse conteúdo normativo compartilhado que a sexualidade é reivindicada e conformada dentro dos limites das normas tradicionais de gênero.

Para produzir uma análise que informe a complexidade social dos conflitos, parto do pressuposto de que as relações de conflito entre pares comporiam um mecanismo socializador assentado em um jogo de diferenças e oposições. Sob este enfoque, podemos conceber o bullying como uma expressão da violência de gênero situada em cenas rotineiras de assimetrias e desigualdades de poder entre mulheres e homens, estabelecidas nas relações entre adolescentes. De tal forma, analisarei as articulações entre violência e gênero a partir das dinâmicas que configuram posições de poder e negociações identitárias nas interações entre meninas na escola.

Como defendem Debert e Gregori (2008), trata-se de vislumbrar uma discussão sobre violência de gênero que problematize os aspectos que constituem as práticas sociais. Ou seja, percorrer as dinâmicas relacionais, discursos e estratégias por meio dos quais o gênero é construído nas tramas de uma violência generificada. Posto que, como coloca Vale de Almeida (1995), é ao nível da negociação cotidiana, das interações carregadas de poder, das reformulações das narrativas de vida constituindo um campo de disputa - que o gênero como processo e prática pode ser apreendido e aprendido. 


\section{Notas metodológicas}

Este estudo etnográfico foi realizado com meninas entre 11 e 15 anos, em duas escolas públicas brasileiras do segundo ciclo do ensino fundamental (6. ${ }^{\circ}$ a $9 .^{\circ}$ anos), sendo uma localizada na cidade de São Paulo e a outra em Salvador, na Bahia.

O trabalho de campo foi empreendido entre fevereiro e junho de 2014, na escola localizada na região noroeste de São Paulo, onde havia um total de 285 discentes, sendo 149 meninas. No período de julho a dezembro de 2014, o cenário da pesquisa foi a escola situada em um bairro da orla marítima de Salvador. Na época da investigação, a instituição atendia um total de 422 discentes no turno matutino, sendo 238 meninas, e no turno vespertino com 289 estudantes, sendo 154 meninas.

A observação participante teve a frequência regular de três dias por semana, nas salas de aula, corredores, pátio e sala dos professores. A imersão mais abrangente em campo ensejou que a produção de dados ocorresse, sobretudo, no presenciar de diálogos e em conversas ${ }^{2}$ com os sujeitos (discentes e agentes institucionais), às quais somam-se 5 entrevistas realizadas em São Paulo e 11 em Salvador, com vítimas e agressoras.

As várias conversas $(\mathrm{CI})$ e entrevistas em profundidade (EP) seguiram um formato fluído, sendo conduzidas informalmente com perguntas abertas baseadas em um roteiro de tópicos relativos ao problema do estudo (Ferreira 2014). Também a confidencialidade contribuiu para que essas ocasiões fossem assimiladas pelas meninas (e meninos) como uma oportunidade de proferir apreciações mais críticas sobre episódios de bullying e temas relativos à sexualidade, além de abordar temas íntimos e delicados como automutilação, violência familiar, abandono paterno e depressão.

Os casos de bullying foram investigados como a montagem de uma colcha de retalhos: além dos registros de campo, importava a comparação e mútua corroboração das declarações de agressoras, vítimas e espectadoras relacionalmente próximas delas. Nesse sentido, a interlocução regular - em conversas e entrevistas semiestruturadas - com alguns professores e as inspetoras de disciplina também foi importante para complementar informações sobre os conflitos e melhor compreender agressoras e vítimas, de modo a ultrapassar respostas lacônicas e evasivas, incialmente fornecidas por algumas adolescentes.

Como estratégia de aproximação das alunas, adotou-se uma interação dialógica, sem censura a temas aventados ou experiências partilhadas. Tal posicionamento potencializou uma rede de colaboração com várias adolescentes, com o aco-

\footnotetext{
Os registros no diário de campo ocorriam em uma sala cedida pela direção das escolas, sempre em seguidas às observações. As conversas foram majoritariamente gravadas, assim como todas as entrevistas.
} 
lhimento por seus grupos de amizade. A participação em reuniões no recreio e em praças após as aulas possibilitou, inclusive, presenciar práticas de bullying. $\mathrm{O}$ papel de observadora também trouxe o incômodo escrutínio, que veio a chancelar uma (necessária) imagem de confiança e credibilidade. O controle exercido pelas meninas consubstanciava-se nos comentários elogiosos/recriminatórios que proferiam sobre vestimentas e concepções sobre gênero e sexualidade enunciadas nas conversações.

Quanto ao método de análise, os dados foram organizados segundo temas, categorias e casos que refletissem padrões homólogos relativos ao bullying e à micropolítica de negociação de feminilidades. O acervo de notas de campo e de transcrições de conversas e entrevistas foi objeto de uma leitura global que gerou a identificação de temas predominantes emergentes do material, os quais, iterativamente, foram sendo consolidados em temas principais, organizados em subcategorias que definiam suas conceituações e elementos característicos (Minayo 2014). Foram definidos os seguintes tópicos: posições de sujeito e categorizações de menina; modos de sociabilidade; modos de organização e hierarquias sociais; relações inter e intragêneros; meios e escopos de poder; definições de bullying e significados da violência. Os trechos de falas e casos aqui apresentados resultam da condensação de significados dominantes e suficientemente ilustrativos de cada tema analisado.

Tendo em vista que as categorias raça/cor e homo/heterossexualidade não fundamentavam as práticas de bullying dos grupos estudados, adotou-se como mote da discussão e recorte metodológico o quadro de referências contextuais à constituição da identidade de gênero e da sexualidade entre meninas heterossexuais. Como veremos a seguir, as adolescentes distinguiam-se umas das outras através de julgamentos avaliativos às performances heterossexuais.

Convém pontuar que a circunscrita representatividade do universo de sujeitos pesquisados e a historicidade dos significados, processos e instituições sociais põem limite à generalização dos resultados da investigação etnográfica. Trata-se de uma compreensão parcial de uma realidade multifacetada, que focaliza as particularidades dos contextos e especificidades dos grupos estudados.

\section{O bullying como cerne do processo cotidiano de regulação moral}

Tal como assevera Butler (1993), a feminilidade é moldada nas relações de disciplina, regulação e punição, que estabelecem a repetição ritualizada de normas, ao espraiar regras, tabus e interdições sociais. O bullying é uma das várias práticas sociais que procedem a reiteração discursiva das diferenças entre mulheres e homens, reproduzindo essa ordenação hierárquica de poder. Interpreto-o como um conjunto de rituais cotidianos de agressões morais e psicológicas entre pares, que delimitam fronteiras ao processo de constituição de subjetividades e identida- 
des generificadas. Esses rituais mostram-se fundamentais para a introjeção e consolidação de características associadas aos modelos de gênero dominantes: por discriminar os posicionamentos dos sujeitos envolvidos, designam definições inequívocas de comportamento feminino apropriado.

Um dos principais empregos sociais do bullying é na competição por popularidade. As adolescentes afirmavam haver entre elas uma disputa "por atenção», «pra aparecer». Popularidade significa apreciação, visibilidade, proeminência social, ou seja, ser distinguível e reconhecível no seu meio. Seguindo o requisito normatizado de moldar uma feminilidade sustentada na aparência, atratividade e conduta decorosa, coletivamente as meninas assumiam a prática de neutralizar possíveis situações de sobreposição ou notabilidade social (Duncan 2004; Ringrose e Renold 2010):

Sempre tem uma que tem uma coisa melhor que a outra, e aí aquela outra já fica criticando... As meninas já gostam de abusar, colocar apelido, porque tão achando que a outra estava se amostrando. (Rita, 12 anos, escola de São Paulo, CI)

A busca da popularidade social confluía com o processo de construção da sexualidade. Um caso emblemático de disputa sexualizada ocorreu na escola de São Paulo, quando algumas meninas do $7 .^{\circ}$ e $8 .^{\circ}$ anos envolveram-se em uma série de confrontos verbais motivados por um estudante recém-chegado. Como explicou Jéssica, era importante ser a primeira a ficar ${ }^{3}$ com um novato, pois além dos comentários entre os colegas, despertava-se o interesse afetivo de outros rapazes:

Todo mundo comenta, todo mundo fica sabendo, enquanto as outras tão só no desejo... Depois ele vai ficar com elas, mas só eu fui a primeira que ele quis. Não é de ficar só por ficar. (Jéssica, 12 anos, CI)

No intuito de afirmar-se como desejável, muitas das meninas e meninos costumavam envolver-se com duas (ou mais) pessoas no mesmo período. Apesar de ser uma conduta bastante disseminada na dinâmica de afirmação da identidade sexual, era tomada como «traição», desenvolvendo rixas. Como sintetizou:

Se ela pegou, eu vou pegar [ficar] também porque sou melhor que ela... aí, depois vão tirar satisfação com a outra. (Estela, 14 anos, escola de Salvador, EP)

A indignação era dirigida a outras meninas, ao invés dos rapazes que as «traíam». Quando assuntadas a respeito, elas traziam como justificativa proteger sua reputação ante uma rival: «você tem que ir lá e mostrar quem você é». Esta performance de defesa da honra é uma forma de reduzir danos sobre a sua imagem

Ficar é um relacionamento afetivo-sexual efêmero, sem vínculo de compromisso e fidelidade. 
e de negociar o seu lugar social, sobretudo, no que diz respeito às desigualdades de poder (Minayo 1994).

Nisso se insere uma gramática hierárquica, cujo binômio corajosa-besta refere-se às interdições da feminilidade normativa. A ideia é «se impor» diante das outras meninas e, em alguns casos, dos rapazes. As adolescentes significavam «coragem» como um símbolo de atividade e força. Contudo, se nos estudos de Neves (2008) e Cordeiro et al. (2010) os comportamentos violentos sinalizam uma estratégia de conquista de respeito e prestígio ante as singularidades do contexto social de segmentos populares, meus achados apontam que a exibição de força por meninas é carregada de ambivalência: trata-se de uma demonstração de poder e (tentativa de) dominação que resulta em visibilidade, mas não na apreciação social, uma vez que a menina que age como «piveta» ${ }^{4}$ marginaliza-se ao se aproximar do universo masculino. É interessante assinalar que a nomeação «piveta» remete não apenas a assunção de características como agressividade, vulgaridade e grosseria por meninas, mas sobretudo faz alusão a sujeitos alegadamente destituídos de «boa» formação moral, e que, em decorrência, apropriam-se de atitudes e comportamentos restritos a adultos.

Este pano de fundo instrumentaliza a regulação do poder mediante a vigilância do comportamento sexual umas das outras. Majoritariamente, fofocas e processos de exclusão envolviam histórias de atividade sexual excessiva e precoce com múltiplos parceiros, por meio das quais elas iam produzindo seu ordenamento social. Um caso exemplar aconteceu na escola de São Paulo: Elena (11 anos) era conhecida - entre rapazes e agentes institucionais - por ser bonita, meiga e discreta. Todavia, ela foi definida pela maioria das colegas como «só fala de homem», «fofoqueira», «cada dia tá namorando com um diferente». Desde que começou a namorar com Ernesto, considerado muito bonito e cobiçado por meninas, passou a ser alvo de intimidação e manipulação social de um grupo rival, em que pontuavam Adriana, Marcela e Lucília, de 12 anos. Adriana tinha sido ficante 5 de Ernesto e ressentiu-se com a exibição pública do relacionamento deste com Elena. Já Marcela acusava Elena de ter ficado com um menino enquanto ela ainda estava com ele.

Indiretamente, o grupo tramou vários boatos de que Elena havia chamado outras meninas de «puta». Essas acusações resultaram em confrontos físicos, ameaças de agressão e o isolamento paulatino de Elena das meninas da escola. Igualmente, foram feitas algumas intimidações diretas: o grupo a seguiu até a sua casa durante alguns dias e na escola a ameaçavam de agressão física.

O termo pivete refere-se a meninos pobres que vivem na rua e estão associados a atividades criminais.

Ficante é a denominação referente à pessoa com quem mantém/manteve um relacionamento afetivo: de «ficar». 
Por fim, Adriana pediu a uma amiga que contasse a Elena que Ernesto a estava traindo com ela. Elena ficou com raiva e resolveu ficar com um amigo dele para se vingar. Adriana contou a história a Ernesto que flagrou Elena ficando com o amigo. Uma fofoca sobre o ocorrido foi contada para a turma toda: alguns rapazes disseram que pensavam que Elena era diferente, mas que tinham se enganado. A intimidação só cessou quando Elena iniciou um novo namoro e Adriana se reconciliou com Ernesto.

Assim como o epíteto de «bicha» entre os meninos (Pascoe 2007; Santos et al. 2017), a onipresente ameaça da estigmatização da «puta» torna-o um poderoso mecanismo disciplinar. O rótulo «puta» atua como um princípio organizador da regulação moral, traçando a fronteira entre normal/desviante no que diz respeito à reputação sexual (Armstrong et al. 2014; Fjaer et al. 2015). Este trabalho de estigmatização mostra como o padrão de gênero e discursos sobre moralidade sexual impactam a constituição da sexualidade pelas adolescentes. Os conflitos vão moldando e restringindo suas subjetividades no que se refere às experiências como sujeitos sexuais e suas habilidades de fazer escolhas fundadas no prazer, desejo e agência (Tolman 2005; Schalet 2009).

O rótulo alcança seu poder retórico através da abjeção (Butler 1990), permitindo que meninas reivindiquem suas próprias feminilidades normativas ao repudiarem outras por seu «desvio». Pode-se afirmar que renegar performances sexuais de colegas é um modo bastante acessível de valorizar sua posição social em relação ao alvo e de obter benefícios sociais desejados. Além de atuar no disciplinamento sexual e na negociação de hierarquias sociais, esse discurso centrado no binômio respeitabilidade-promiscuidade estabelece padrões de aparência e comportamento para as adolescentes. Ou seja, não fornece meramente rótulos descritivos, mas posições de sujeito que as convidam a olhar e compreender seu mundo social de maneiras específicas.

A categorização de desviantes torna-se fundamental por prover conhecimento (do senso comum) sobre conjuntos de pessoas. Ela infunde predicados normativos e comportamentos morais que são usados para contrastar grupos e moldar o nosso ideário de gênero. A força coercitiva dessa prática consiste em tornar verossímil as características negativas atribuídas, limitando as possibilidades de ação das rotuladas.

Como afirma Crapanzano, as «categorias são usadas retoricamente, e não apenas semanticamente, em qualquer interpretação» $(2002,443)$. Em tom argumentativo, à nomeação "puta» seguiam-se justificativas relacionadas a uma conduta sexual desbragada. Tal e qual a descrição de Elena, caracterizações de outras adolescentes convergiam em frases padronizadas, constantemente repetidas e aparentemente fantásticas: «Marisa ficou com 28 meninos daqui, só no ano passado»; «Marta já pegou quase todos os meninos da sexta série»; «Elisa tem um jeito muito pra frente, fala de sexo, de homem, de um jeito vulgar».

Estas avaliações de conduta operam na reprodução e naturalização do cará- 
ter distintivo do gênero e dos arranjos institucionais que os sustentam. Em repetidos episódios, mantém-se ou modifica-se a hierarquia social, inclui-se ou exclui-se pares, contribuindo para o estabelecimento de padrões normalizados.

Tanto o bullying sofrido por Elena quanto as falas supradestacadas evidenciam o papel da fofoca difamatória como um meio de manipular reputações, podendo ser vista como uma «atividade furtiva pela qual dossiês morais de outras pessoas são constantemente revistos» (Boehm 1999, 73). Por ser uma conversa imbuída de um entendimento tácito acerca de determinado evento ou situação, fofocas tornam-se relevantes para o aprendizado sobre os valores e normas do grupo. Isto porque, para além de um julgamento, o mexerico é uma forma de punição que comunica comportamentos estigmatizáveis e publiciza a desaprovação social (Baumeister et al. 2004).

O caráter genérico, intercambiável e mesmo apócrifo da imputação resume a ideia de uma «puta mítica», enquanto uma categoria usada para delimitar o aceitável. O poder do rótulo consiste em ser aplicado a qualquer momento, geralmente por razões alheias ao comportamento sexual (Ringrose 2008; Miller 2016). Isso sugere que o estigma da «puta» é mais sobre a regulação do desempenho público do gênero do que a regulamentação das práticas sexuais privadas. Esse modelo discursivo não requer a existência de vadias «reais», qualquer menina pode preencher provisoriamente a posição.

De facto, com base na avaliação dos outros, a realização da feminilidade não é automática nem segura. A tensão instaurada no entendimento de estarem submetidas à vigilância das colegas é sintetizada pela constância com que mencionavam a permanente ameaça de «difamação». De acordo com Connell (2005), o medo de ser desacreditado funciona como um mecanismo de controle por gerar certa cumplicidade com o modelo dominante de gênero, que, por sua vez, demanda a subordinação de outras feminilidades consideradas desviantes. É a razão pela qual verifiquei contradições entre discursos e práticas com o uso de estratégias de encobrimento de condutas «inapropriadas». Mesmo sem aderir ao modelo normativo, as meninas vão aprendendo a cuidar de suas atitudes, gestual e falas. Regular seus corpos e estilos de vida é a forma possível (apesar de não afiançável) de manterem-se afastadas de problemas relativos à estigmatização.

As fofocas rotineiramente reforçavam a desigualdade de gênero ao posicionar meninas como atores culpáveis, ao passo que invisibilizavam as escolhas e ações dos meninos. Quando assuntadas sobre a participação dos rapazes no ato desviante, as respostas convergiam em ignorá-los, intensificando as críticas morais às colegas. Isso é indicativo de como meninas e meninos encontram padrões distintos em suas experiências de heterossexualidade. E, igualmente, de como essas histórias promovem (e consolidam) o entendimento do que é e do que não é um comportamento sexual permissível para elas próprias. Com efeito, terminam por assimilar o papel de guardiãs da moralidade sexual (Fjaer et al. 2015). 
A disseminação de boatos sexuais é a forma mais comum de rebaixar moralmente o alvo. Desacreditar alguém requer desconstruir uma imagem já consolidada da pessoa. Essa prática de inferiorização é parte relevante nas definições e negociações de sexualidade feminina normativa, possibilitando ponderar a dor psicológica vivenciada nesse processo. Tal ideia é ilustrada por Elena, cujo bullying sofrido foi aqui relatado:

Tudo isso só pode ser pra eu me sentir culpada, que eu era errada. E eu pensei assim. Muitas vezes, fiquei pensando o que eu tinha feito pras meninas. Eu não faço parte, só tenho duas amigas, as outras não gostam de mim nem falam comigo. (EP)

Como já observado, o conteúdo das práticas de bullying centra-se não no que as meninas fazem, mas como elas se apresentam (ou o que representam) no meio social e o que significa ocupar uma posição abjeta. Essa presença rotineira do bullying ajuda a situar como as meninas costumam envolver-se mais com os padrões de gênero do que suas experiências sexuais. Isso ocorre também pelo pouco apoio familiar e escolar que dispunham para conhecer e compartilhar experiências de sexualidade na adolescência como a perda da virgindade, práticas e relações afetivo-sexuais. Tal cenário nutre um círculo vicioso que consolida o ideário do desejo e prazer sexual feminino como um tabu social.

\section{Bullying como jogos de posicionamento: (Re)produzindo discursos, nego- ciando identidades de gênero}

Em ambas as escolas, havia uma tácita dicotomia maturidade-infantilidade que condicionava um afastamento pronunciado entre as meninas «mais velhas»e as «mais novas» no que tange ao comportamento, ocupação de espaços de sociabilidade, estabelecimento de interações regulares e de relacionamentos afetivo-sexuais. Todavia, um ponto de análise fundamental é atentar-se à combinação de fatores contextuais na modelagem das práticas coletivas de bullying pelos sujeitos. A organização disciplinar da escola de Salvador é emblemática nesse sentido: para evitar conflitos entre estudantes com diferença de força física separou-se as turmas do sexto e sétimo anos e do oitavo e nono anos por pavilhões de aula e uniformes de cores diferentes (branco e azul, respectivamente). Essa separação foi transmutada em distinção social pelas meninas das últimas séries ${ }^{6}$ que valiam-se de categorizações antagônicas, inter-relacionadas com idade e feminilidade, para cimentar seu poder social.

Na escola de Salvador, o $8 .^{\circ}$ ano era oferecido exclusivamente no turno vespertino e o $9 .^{\circ}$ ano apenas no matutino. 
As diferenças de códigos culturais de gênero foram incorporadas nas categorias de menina «foveira» e «plantada». Conforme situa Butler (1993), são as categorias que distribuem, identificam e produzem práticas divisivas e sugerem as regras locais a serem apreendidas. Nesse sentido, a nomeação «foveira» ${ }^{7}$ era usada pelas meninas mais velhas para se referir às menores que «são foguentas [têm desejo desbragado]», por ainda não saberem como lidar com a sua sexualidade.

Em contrapartida, as adolescentes maiores mostravam-se mais conscientes das pressões sociais para se tornarem «mais calmas e quietas», daí a autoidentificarem-se como «plantadas». O termo «plantada» denota uma atitude de conformidade e de bom comportamento associados ao «tomar juízo» e «assentar-se». Em entrevista, Bethânia (9..$^{\circ}$ ano, 14 anos) elucidou o fundamento destas categorias relacionais:

É a mesma coisa de puta, não tem nenhuma diferença... porque é uma menina que gosta de ficar usando uma calça toda atochada... mostrando a polpa da bunda, coloca a camisa do uniforme pra aparecer a barriga, sai andando rebolando. [...] as meninas do sexto e do sétimo estão namorando agora e são muito atiradas. Quer pegar todo mundo... Não são todas, mas a maioria é... As meninas do oitavo e do nono já tem mais maturidade, já sabe ficar na sua, mais discreta.

A assimetria social é realizada através do facto de que apenas um grupo pode ou deve assumir o direito de enquadrar um modo de ser menina, regulando a atividade das outras. Para tanto, as meninas «plantadas» costumavam recorrer a «gastação», um modo de escárnio que servia à intimidação e ao aviltamento das «foveiras». A «gastação» assemelhava-se às práticas de sociabilidade jocosa; entretanto, ao contrário dessas troças, se restringiam ao ridículo de caráter discriminatório, que realçava alinhamentos sociais e fronteiras identitárias.

Esse ritual expressava uma performance dramática composta de ações que seguiam um mesmo script (Thorne 1997), depreciando a infantilidade vis-à-vis atitudes de «piveta», má aparência e falta de atratividade sexual. A dramatização lhes possibilitava mostrarem-se simbolicamente superiores ao enunciarem que sabem como se vestir, falar e comportar-se. Nesse sentido, a experiência sexual também é invocada para chancelar sua popularidade, como já abordado aqui. A constância desses jogos de posicionamento ajuda a entender a importância de cuidar da imagem projetada diante dos outros (Butler 1993; Goffman 2008; Tomasini 2013). Enquanto uma afirmação de si mesmas, visam preservar uma situação e uma posição segura para as meninas «plantadas». Nesta nota de campo temos um grupo de amigas do oitavo ano «gastando» com Ivana (6. ${ }^{\circ}$ ano, 12 anos):

Foveira é uma gíria usada nos segmentos populares da Bahia para referir-se às mulheres consideradas demasiado liberais (vulgar e sexualmente apelativas) e que se vestem de forma provocadora. Alude à impureza, uma vez que a pele foveira é efeito da descamação, tida como resultante do descuido com a aparência. 
Vanessa: Você devia era fazer umas tranças ou alisar esse cabelo, 'tá muito inchado, 'tá muito esquisito.

Paula: 'Cê não fala, não é? Fica sempre com essa cara?

Vanessa: Essa cara feia...

Teresa: Olha o laço [no cabelo]! E esse colete?

Júlia: Mas gente! Quem ia querer essa mocoronga [pindérica]? Só se o menino é maluco... ou cego.

Paula: Ela precisa melhorar muito...

Nesses episódios de violência sutil, a conversão de diferenças em desigualdades sociais tem como sustentáculo a coerção pelo constrangimento (Goodwin 2006; Tomasini 2013). O embaraço ocasionado pela «gastação» nos remete à ideia goffmaniana da necessidade de dominar o papel, posto que os «falhanços» de desempenho resultam em constrangimento. Ringrose e Renold (2010) já haviam notado que essas experiências de vergonha impulsionam tomadas de decisão referentes à identidade constituída, tornando-se fator-chave nos processos de organização e controle social dos sujeitos que passam a antecipar comportamentos a evitar.

Igualdade e diferença, padrões de inclusão e exclusão são tecidas nesse sistema de atividades integradas de construção de desigualdade. Essa condição de desigualdade desenvolve a regulamentação invocada pelas adolescentes como obrigatória para elas próprias, que, por sua vez, articula a sua obrigatoriedade. Ao descrever um conjunto de qualidades necessárias para meninas tornarem-se mulheres, a prática de bullying adquire valor ímpar na socialização de gênero. A força desse tipo de intimidação está em sua capilaridade social: uma rede de relações que tenta impor o alinhamento pelo olhar, pela visibilidade das submetidas e, consecutivamente, produzem efeitos de poder. Trata-se de situar a importância e os significados das várias regras tradicionais de procedimento, conferindo inteligibilidade cultural ao ser mulher (e ao ser homem).

A percepção é de que a diferenciação social pela divisão etária pontua o arco do processo de aprendizagem de regras e convenções morais de gênero que ocorre ao longo da adolescência. Conforme aponta Tomasini (2013), essa fase de transição que culmina na «pessoa crescida» requer criar um antagonismo que permita a diferenciação relativa a esse outro marcado como um eu pretérito. Assim, a maturidade ou imaturidade são definidas na dinâmica de avaliação e reconhecimento do grupo de pares, que estabelece critérios de similitudes e diferenças.

Citando-se como exemplo, algumas meninas mais velhas atribuíam o comportamento «foveiro» ao afã e ao entusiasmo que se sente ao «experimentar algo novo». As narrativas assinalavam que esse movimento de experimentação sexual é um processo pelo qual também haviam passado no período etário entre os 11 e 12 anos. Dada a ênfase conferida, parecia ter a força de um axioma: as meninas menores são tidas como mais «assanhadas», por ainda não terem aprendido a se comportar adequadamente. 
Esse aprendizado desenvolve-se com o peso decisivo da pressão exercida pelos pares. Além da difamação por colegas de ambos os sexos, as meninas tinham que lidar com o assédio sexual (bolinadas e insultos) de rapazes. Afinal, as relações de constrangimento desempenhadas no bullying aportam à normalização do sexismo e da violência como forma de moralização da sexualidade feminina entre pares. Quando alguma menina tentava se defender da coerção sexual sofrida, costumeiramente era questionada pelos jovens: «Ah, mas você não pega os meninos todos, por que não eu também?» Uma provocação que sintetiza como o trabalho de desvalorização moral aqui descrito servia de justificativa para o assédio. De facto, ao impelir à assimilação de estereótipos de gênero, esse mecanismo coercitivo reforça o papel subalterno das mulheres em relação aos homens. E esse reforço das fronteiras entre o feminino e o masculino nas práticas cotidianas culmina em um processo de feminilização.

À guisa de sintetizar os efeitos do bullying na construção identitária de gênero, atenho-me à importância da regulação moral para a conformação de condutas equilibradas. As práticas e significados articulados em torno da feminilidade tradicional são marcados por uma série de exigências culturais inscritas na tensão entre os dois polos constitutivos da identidade feminina (pureza-poluição), sem pender a uma das extremidades. Há de se levar em conta o peso dessa problemática na constituição da feminilidade pelas adolescentes: elas devem ser, mas não muito, autoabsorvidas sobre sua aparência; devem ser atraentes, mas não vistas como sexualmente expansivas; devem ser bem-comportadas, mas não vistas como «bestas»; notadas e apreciadas pelos colegas, mas não chamar muita atenção sobre si próprias, e assim por diante (Currie et al. 2007). De tal modo, a identidade feminina é construída por esses jogos de diferenças e oposições que não confluem entre polos de um «eu» e um «outro» exterior como a masculinidade hegemônica, mas, sim, demanda conformar, situacionalmente, polos contrários.

\section{Considerações finais}

A discussão sobre violência de gênero no ambiente escolar reforça a necessidade de a instituição voltar-se para práticas educativas que desestabilizem e desconstruam a naturalidade de ações e discursos de conteúdo sexista pelos estudantes. Sendo a escola um espaço em que são reproduzidos padrões assimétricos e de desigualdades generificadas, faz-se necessário problematizar o gênero como prática, constructo simbólico e princípio estrutural nas relações entre os vários sujeitos. Implica, dentre outras questões, refletir sobre os símbolos culturalmente disponíveis e as atribuições relativas ao que é ser homem e mulher em nossa sociedade.

Em prol da assimilação da alteridade no processo de construção identitária pelos estudantes, as práticas educativas e intervenções nos conflitos precisam con- 
siderar a dimensão normativa que os constitui. O bullying materializa as barreiras relativas à normativa de gênero nas relações entre adolescentes (Miller 2016; Miranda e Maia 2017; Santos et al. 2017), barreiras essas que exprimem a reprodução da desigualdade de gênero experimentada no desenvolvimento de sua sexualidade. Atento, assim, ao perigo reducionista de vislumbrá-lo como um ato de indisciplina ou punição direta e unicamente vinculado a sentimentos como vingança, raiva, ciúme ou mágoa. O poder, a popularidade e o status são categorias-chave que mobilizam e dependem de ações discriminatórias para se manifestarem efetivamente (Duncan 2004; Armstrong et al. 2014). É nesses termos que o bullying intensifica o efetivo social de convencimento sobre a pertinência das características socialmente apreciadas, mas, sobretudo, o entendimento da gramática das normas sociais de gênero.

\section{Referências bibliográficas}

Armstrong, Elizabeth A., Laura Hamilton, Elizabeth M. Armstrong, e J. Lotus Seeley. 2014. «Good girls: gender, social class, and slut discourse on campus». Social Psychology Quarterly 77 (2): 100-122. DOI: https://doi.org/10.1177/0190272514521220

Baumeister, Roy, Liqing Zhang, e Kathleen Vohs. 2004. «Gossip as cultural learning». Review of General Psychology 8 (2): 111-121. DOI: https://doi.org/10.1037/1089-2680.8.2.111

Boehm, Christopher. 1999. Hierarchy in the forest: the evolution of egalitarian behavior. Cambridge: Harvard University Press.

Butler, Judith. 1990. Gender trouble: feminism and the subversion of identity. New York: Routledge.

Butler, Judith. 1993. Bodies that matter: on the discursive limits of «sex». New York: Routledge.

Connell, Raewyn. 2005. Masculinities. Berkeley, CA: University of California Press.

Cordeiro, Rosineide, Evandro Barbosa Filho, Giselle Maria dos Santos, Luanne Oliveira, e Raíssa Araújo. 2010. «Meninas de moral: experiências socioeducativas em um bairro popular do Recife». Psicologia: Ciência e Profissão 30 (1): 188-199. DOI: https://doi.org/ 10.1590/S1414-98932010000100014

Crapanzano, Vicent. 2002. «Estilos de interpretação e a retórica de categorias sociais». In Raça como retórica: a construção da diferença, organizado por Yvonne Maggie e Cláudia Rezende, 441-458. Rio de Janeiro: Civilização Brasileira.

Currie, Dawn, Deidre Kelly, e Shauna Pomerantz. 2007. «The power to squash people: understanding girls' relational aggression». British Journal of Sociology of Education 28 (1): 23-37. https://doi.org/10.1080/01425690600995974

Debert, Guita, e Maria Filomena Gregori. 2008. «Violência e gênero: novas propostas, velhos dilemas». Revista Brasileira de Ciências Sociais 23 (66): 165-211. DOI: https://doi.org/ 10.1590/S0102-69092008000100011

Duncan, Neil. 2004. «It's important to be nice, but it's nicer to be important: girls, popularity and sexual competition». Sex Education 4 (2): 137-148. DOI: https://doi.org/10.1080/146 81810410001678329

Ferreira, Vitor Sérgio. 2014. «Artes e manhas da entrevista compreensiva». Saúde e Sociedade 23 (3): 979-992. DOI: https://doi.org/10.1590/S0104-12902014000300020 
Fjaer, Eivind, Willy Pedersen, e Sveinung Sandberg. 2015. «I'm not one of those girls: boundary-work and the sexual double standard in a liberal hookup context». Gender $\mathcal{E}$ Society 29 (6): 960-981. DOI: https://doi.org/10.1177/0891243215602107

Goffman, Erving. 2008. A representação do eu na vida cotidiana. Petrópolis: Vozes.

Goodwin, Marjorie. 2006. The hidden life of girls: games of stance, status and exclusion. Malden, MA: Blackwell.

Miller, Sarah. 2016. «How you bully a girl: sexual drama and the negotiation of gendered sexuality in high school». Gender \& Society 30 (5): 721-744. DOI: https://doi.org/10.1177/ 0891243216664723

Minayo, Maria Cecília. 1994. «A violência social sob a perspectiva da saúde pública». Cadernos de Saúde Pública 10 (1): 7-18. DOI: https://doi.org/10.1590/S0102-311X1994000 500002

Minayo, Maria Cecília. 2014. O desafio do conhecimento: pesquisa qualitativa em saúde. São Paulo; Rio de Janeiro: Hucitec; Abrasco.

Miranda, Ana Paula, e Bóris Maia. 2017. «Olhares, xingamentos e agressões físicas: a presença e a (in)visibilidade de conflitos referentes às relações de gênero em escolas públicas do Rio de Janeiro». Horizontes Antropológicos 23 (49): 177-202. DOI: https:// doi.org/10.1590/s0104-71832017000300007

Neves, Paulo Rogério. 2008. «As meninas de agora estão piores do que os meninos: gênero, conflito e violência na escola». Dissertação de mestrado, Universidade de São Paulo.

Pascoe, Cheri. 2007. Dude, you're a fag: masculinity and sexuality in high school. Berkeley: University of California Press.

Ringrose, Jessica. 2008. «Just be friends: exposing the limits of educational bully discourses for understanding teen girls' heterosexualized friendships and conflicts». British Journal of Sociology of Education 29 (5): 509-522. DOI: https://doi.org/10.1080/0142569080 2263668

Ringrose, Jessica, e Emma Renold. 2010. «Normative cruelties and gender deviants: the performative effects of bully discourses for girls and boys in school». British Educational Research Journal 36 (4): 573-596. DOI: https://doi.org/10.1080/01411920903018117

Santos, Hugo, Sofia Marques da Silva, e Isabel Menezes. 2017. «Para uma visão complexa do bullying homofóbico: desocultando o quotidiano da homofobia nas escolas». ex æquo 36: 117-132. DOI: https://doi.org/10.22355/exaequo.2017.36.07

Schalet, Amy. 2009. «Subjectivity, intimacy, and the empowerment paradigm of adolescent sexuality: the unexplored room». Feminist Studies 35 (1): 133-160.

Simmons, Rachel. 2011. Odd girl out: the hidden culture of aggression in girls. New York: Harcourt.

Thorne, Barrie. 1997. Gender Play: girls and boys in school. New Jersey: Rutgers University Press.

Tolman, Deborah. 2005. Dilemmas of desire: teenage girls talk about sexuality. Cambridge: Harvard University Press.

Tomasini, Marina. 2013. «Hacerse el malo: interacciones cotidianas entre estudiantes varones de primer año de escuelas secundarias de Córdoba, Argentina». Sexualidad, Salud y Sociedad (15): 86-112. DOI: https://doi.org/10.1590/S1984-64872013000300005

Vale de Almeida, Miguel. 1995. Senhores de si: uma interpretação antropológica da masculinidade. Lisboa: Fim de Século. 
Jamile Guimarães. Socióloga, doutora em Saúde Pública e pesquisadora associada na área de Gênero, Sexualidade e Saúde do Departamento de Saúde, Ciclos de Vida e Sociedade da Faculdade de Saúde Pública da Universidade de São Paulo, Brasil. Realizou estágio de pesquisa no CIES-Instituto Universitário de Lisboa, com bolsa da CAPES. Desenvolve investigações interdisciplinares sobre juventude, gênero, sexualidade e promoção da saúde com enfoque nos processos de construção identitária em ambientes de participação social, comunidades empobrecidas e escolares.

Endereço eletrônico: mile.guimaraes@gmail.com

Artigo recebido a 2 de junho de 2018 e aceite para publicação a 1 de setembro de 2018. 